\title{
PRÁTICAS DE FORMAÇÃO DO TRABALHADOR RESULTADOS E INDICADORES
}

Inês Amaro da Silva*

SINTESE - O avanço cientifico e tecnológico e as transformações econômicas, políticas e sociais em curso colocam em um novo lugar a questão do trabalho e da formação dos trabalhadores, que passa a referir-se ao desenvolvimento humano global e abrangente, em niveis intelectuais, emocionais, sociais, politicos e comportamentais. As novas realidades demandam explicitar processos, relações e práticas de formação de forma a assinalar algumas rupturas necessárias e construir dimensões e indicadores que apontem caminhos para modelos sociopedagógicos voltados à instauração da competência e à ampliação da cidadania.

PALAVRAS-CHAVE - práticas de formação, resultados, indicadores.
ABSTRACT - The ongoing scientific and technological advance, as well as the economical, political and social transformation locates the issue of work and the training of workers in a new place. The issue begins to refer to the global and unabridged human development in the intellectual, emotional, social, political and behavioral levels. The new reality demands that one explain processes, relations and practices of formation, in order to signal some necessary ruptures and to build dimensions and indicators that will show ways to reach sociopedagogical models focused on the instauration of competence and on the broadening of citizenship.

KEY WORDS - practices of formation, result, indicators.

\section{Introdução}

Num mundo competitivo, plural, excludente e contraditório, marcado pela crescente necessidade de mobilizar a totalidade das capacidades, aptidões e habilidades humanas para desenvolver aprendizagem, conhecimento, informação e trabalho, os novos modelos de formação precisam construir formas de articular as demandas dadas pelo mundo produtivo, expressas na categoria competência, com as demandas sociais de fortalecimento e ampliação da cidadania, pois as condições materiais em que as pessoas vivem também formam ou deformam, humanizam ou desumanizam as relações sociais.

* Mestre em Serviço Social, consultora em desenvolvimento humano-social.

\begin{tabular}{|l|l|l|l|l|l|}
\hline VERITAS & Porto Alegre & v. 43 & $\mathrm{n}^{2}$ especial & Dezembro 1998 & p. 27-34 \\
\hline
\end{tabular}


Este artigo apresenta, sinteticamente, alguns resultados da investigação "Competência e cidadania: uma articulação possivel?" onde se procurou captar como o Serviço Social da Indústria do Rio Grande do Sul (SESI-RS) tem contribuído para a formação da competência e da cidadania junto aos trabalhadores, no período de 1990 a 1996, através de práticas voltadas ao atendimento de carências e necessidades sociais constituídas nas relações sociais de trabalho. Embora a formação não apareça no discurso institucional, é sobre os aspectos socioemocionais e comportamentais do trabalhador que essas práticas incidem - aspectos esses hoje fundamentais para o capital - instaurando hábitos, atitudes e comportamentos sintonizados às demandas dadas nas relações de disputa entre os agentes dos campos político, econômico e social a cada momento histórico.

Os pressupostos epistemológicos da pesquisa implicaram articular teoriamétodo-dados de forma đinâmica e interdependente, de modo que as dimensões e os indicadores da formação para a competência e para a cidadania, construídos a priori, ${ }^{2}$ foram relativizados ou fortalecidos no movimento contínuo de confronto entre racional e real. Os aspectos apresentados expressam alguns resultados e indicadores desse processo de instauração de práticas que tendam a formar competência e a ampliar o exercício da cidadania.

\section{Instituição e agentes: propostas e práticas de formação}

As relações de disputa entre os agentes sociais na dinâmica estrutural do campo do poder e suas expressões no processo institucional conferem um caráter de descontinuidade nas ações de formação desencadeadas pelo Serviço Social da Indústria do Rio Grande do Sul. A partir de 1989/90 essa descontinuidade se manifesta por uma nova orientação na instituição, traduzida por politicas, diretrizes e estratégias reveladoras de um discurso de modernização, qualidade, produtividade e competitividade e pela implantação ou reordenamento de programas e atividades que têm o potencial de instaurar competência e cidadania junto aos trabalhadores.

As atividades pesquisadas - Grupos de Trabalhadores, Educação de Adultos, Prevenção ao Uso de Drogas no Trabalho, Educação para a Saúde e Cursos da Comissão Interna de Prevenção de Acidentes (CIPA) possuem conteúdo formativo expresso na preocupação em incorporar as demandas do mundo do trabalho e capacitar o trabalhador como cidadão, nos diferentes papéis sociais que desempenha. Entretanto, é a realização dessas propostas pelos técnicos da instituição (assistentes sociais, médicos do trabalho, técnicos em segurança do trabalho e pedagogas), que dá "forma" às práticas de formação, a seguir analisadas.

1 Dissertação de Mestrado desenvolvida junto à linha de pesquisa Formação, Trabalho e Cidadania, coordenada pela Professora Julieta Beatriz Ramos Desaulniers no Curso de Mestrado em Serviço Social e Faculdade de Filosofia e Ciências Humanas da PUCRS. O pressuposto central é que a produção do social se dá na articulação entre estruturas objetivas e subjetivas e por movimentos descontinuos associados às relações de disputa entre os agentes sociais na dinâmica estrutural dos campos que compõem o espaço social.

2 O quadro de operacionalização das categorias centrais da investigação está no final do artigo. 
Os agentes formadores mobilizam uma rica diversidade de saberes no processo de formação. São saberes formais e informais, advindos da formação profissional de cada um, de diferentes disciplinas científicas, das ações, normas e discursos institucionais, bem como da experiência profissional cotidiana e da totalidade das suas experiências no mundo social, visão de mundo e valores adquiridos pela participação em diferentes contextos formadores. É na múltipla articulação desses saberes e na relação estabelecida com trabalhadores que se constitui a formação.

Por outro lado, as práticas em equipes interdisciplinares e interinstitucionais, ainda isoladas e incipientes, revelam condicionantes intra e interpessoais, estruturais e da cultura institucional que são dificultadores para uma abordagem coletiva e cooperativa das práticas sociais.

Quanto à articulação entre as dimensões intelectual, emocional e do agir no processo de formação, são utilizadas estratégias que caracterizam criatividade e versatilidade metodológica, embora em graus diferentes em cada atividade. Os métodos, técnicas, recursos audiovisuais e lúdico-pedagógicos, na forma como são trabalhados, viabilizam integrar idéias, sentimentos e atitudes.

Ainda, os métodos e técnicas utilizados privilegiam a participação dos formandos no desenvolvimento das práticas e a construção de relações democráticas entre os agentes. Se "participar" muitas vezes limita-se a "fazer perguntas", tendo seu conteúdo sociopolítico pouco trabalhado, outras vezes pode chegar a estimular um novo comportamento como trabalhador e como cidadão, pela autocrítica sobre a própria não-participação no cotidiano.

Sobre essa questão, os técnicos apontam que também os trabalhadores têm resistência para expressar saberes, percepções e emoções, em decorrência tanto da desconfiança ou da crítica em relação às propostas, quanto de uma vivência político-social e cultural marcada por relações sociais paternalistas e autoritárias e por uma percepção dissociada e fragmentada do homem no processo produtivo e na vida social. Às faltas de permissão externa associam-se as faltas de permissão interna; logo, trabalhar as dimensões afetivas junto com as dimensões cognitivas e desenvolver a participação crítica requer ampliar a subjetividade e construir novas relações sociais.

Nas relações de đisputa entre agentes formadores e formandos movimenta-se o processo democrático e flexibilizam-se em alguma medida as relações de saberpoder. A relação democrática com uma figura de autoridade, representada no agente formador, contribui para que o trabalhador experimente novas relações também no trabalho, na família ou na comunidade.

As dimensões e indicadores da competência e da cidadania aparecem de diferentes formas e com freqüências e intensidades variadas, caracterizando uma heterogeneidade decorrente das diferentes naturezas de cada atividade investigada, das áreas do saber técnico-científico e do habitus dos agentes.

Essas diferenças enriquecem e dinamizam as práticas, bem como colocam o desafio da construção interdisciplinar, pois a heterogeneidade revela também a falta de uma visão sócio-pedagógica e de uma orientação valorativa e teóricometodológica compartilhada entre os agentes nas práticas de formação. 


\section{Resultados das práticas de formação para os trabalhadores}

O fenômeno social da formação se concretiza na articulação entre as estruturas objetivas que o compõe e as estruturas subjetivas, necessidades, desejos e motivações dos agentes, representados em formas de pensar, sentir e agir produzidas nesta relação interioridade/exterioridade. Os resultados das práticas de formação podem ser visualizados, assim, a partir dos saberes, capacidades e habilidades aprendidos e pelas mudanças na vida pessoal e profissional dos trabalhadores.

Os saberes aprendidos abrangem aspectos sociais, políticos e comunicativos, integrando a aprendizagem a nivel da consciência (informação), da afetividade (sensibilização) e da atividade (ação) e ampliando capacidades e habilidades para enfrentar e resolver situações-problema vividas no cotidiano, através de mudanças atitudinais e comportamentais.

Tais mudanças ocorrem significativamente em termos da competência interpessoal - flexibilidade, confiança, reconhecimento e aceitação de diferenças, melhor conhecimento de si próprio, melhor interação com o outro - e da comunicação, pelo rompimento de distâncias e barreiras antes vistas como quase intransponiveis - da ruptura com um padrão de comportamento baseado no medo de exporse e de não ser aceito à busca de melhor qualidade na comunicação estabelecida com os outros - instâncias essas que são fundamentais para a competência e para a cidadania, pois a expressão é uma condição para qualificar a participação social.

A reflexão sobre situações que afetam o cotidiano de vida e trabalho e o desenvolvimento de capacidades e habilidades possibilita que o trabalhador se comprometa com a gestão de sua vida profissional, pessoal, familiar e comunitária, buscando garantir direitos, realizar necessidades e desejos e viver com mais qualidade. As práticas contribuem para ampliar as formas de ler a realidade, acessar o mundo e com ele relacionar-se, ter uma visão crítica das relações sociais e da responsabilidade na proteção da saúde e segurança individual e coletiva, idealizar projetos profissionais e assumir novos posicionamentos enquanto trabalhador e enquanto cidadão.

A participação nas atividades repercute também positivamente na autoestima dos trabalhadores face ao "saber mais", confiar nas suas potencialidades e capacidades e sentir-se útil e importante. Os sentimentos positivos sobre si mesmo motivam novas experiências no contexto imediato onde interage com outros agentes sociais, de seu grupo ou de outros grupos, por exemplo nas relações de trabalho e de autoridade dentro da empresa produtiva ou nas relações com instituições sociais com as quais entra em contato no cotidiano, ampliando também o acesso às mesmas. Especialmente quanto às relações de trabalho, algumas rupturas nos padrões de benevolência e autoritarismo em direção a relações participativas e democráticas permitem falar de uma incipiente politização do espaço da produção, no âmbito investigado.

Uma vez experimentada a ruptura, novos comportamentos e atitudes tendem a reforçar a segurança para ousar, criar e ter iniciativas e o sentimento de "ter direito a ter direitos" como trabalhador e como cidadão, estimulando a participação crítica e criativa na realidade. Essa articulação entre saberes, capacidades e 
habilidades instaurados permite, no cotidiano, uma práxis mais competente. Considerando que é na vida cotidiana, nos espaços da empresa, da casa, da comunidade que se dão as relações sociais, as pequenas mudanças nessas relações e ações cotidianas contribuem para a construção de uma nova intersubjetividade e de uma relação entre ser competente como trabalhador e cidadão.

As práticas de formação, ao mobilizarem diferentes dimensões, aptidões e saberes dos trabalhadores, podem facilitar a descoberta e a colocação em ato de outras alternativas de inserção social e de trabalho que, do contrário, talvez sequer pudessem cogitar. Ou seja, as práticas ao mesmo tempo em que desenvolvem competência, ampliam e fortalecem o exercício cotidiano da cidadania e viceversa.

\section{Formar para competência e para cidadania - alguns indicadores}

As práticas de formação pesquisadas têm a potencialidade de obter mais resultados na formação do trabalhador-cidadão, dentro das atuais exigências do mundo do trabalho e do mundo social como um todo, à medida que contemplarem sistematicamente as dimensões e indicadores investigados e que fortalecerem a construção de modelos sociopedagógicos de formação. Ainda que essas dimensões e indicadores não dêem conta da totalidade dos elementos envolvidos na dinâmica das ações formativas, traduzem aspectos importantes para o desenvolvimento socioemocional, político e comportamental, com vistas a instaurar competência e cidadania. São eles:

- interdisciplinaridade e complexificação de saberes em todas as instâncias, no planejamento das ações institucionais e nas práticas dos agentes formadores, no trabalho em equipe intra e interinstitucional e na mobilização de saberes disciplinares dos diferentes campos do conhecimento e saberes advindos de outras formas de apreensão do real, do cotidiano de vida e trabalho e das relações sociais, na direção da transdisciplinaridade;

- articulação teoria - prática e articulação cognição-afeto, confrontando teoria e realidade cotidiana num movimento constante entre racional e real, problematização, informação, vivência e experiência, trabalhando integradamente as dimensões do intelecto e das emoções, de forma a reconhecer e ampliar as subjetividades e desenvolver competência socioemocional e política. Isso implica também trabalhar as forças restritivas e as forças propulsoras da mudança, a auto-estima e as resistências dos formandos e dos formadores no processo de construção de modelos pautados em novos paradigmas que indicam a necessidade de rupturas com crenças, valores, formas de sentir e agir profundamente arraigadas no habitus dos agentes sociais;

- relação democrática nas relações de saber-poder e nas necessidades interpessoais experimentadas entre os agentes formadores e formandos, praticando a complementaridade, o respeito e a confiança, bem como a gestão participativa no planejamento e na execução das práticas de formação. A participação dos trabalhadores/formandos refere-se ainda à ampliação do acesso às mesmas, no sentido da democratização dos recursos e dos saberes hoje exigidos para competir por uma inserção social qualificada; 
- riqueza e criatividade metodológica através de técnicas, instrumentos e recursos metodológicos articulados e trabalhados para viabilizar a diversificação e complexificação đe saberes, a articulação teoria-prática e cognição-afeto e as relações democráticas, possibilitando junto aos formandos a ampliação de capacidades e habilidades como iniciativa, criatividade, senso de equipe, entre outras. Para tanto, a abordagem da dinâmica e dos processos grupais e a educação de laboratório são instrumentos com amplas possibilidades de utilização no caminho da capacitação para aprender a aprender;

- formação dos agentes formadores tendo em vista o desenvolvimento da competência enquanto formador e cidadão e para construção coletiva do aporte teórico-metodológico e valorativo das práticas de formação, incluindo as dimensões e indicadores aqui sugeridos;

- avaliação participativa e sistemática em ações contínuas, a partir de indicadores qualitativos e quantitativos previamente definidos para acompanhar 0 processo, mensurar resultados e fazer melhorias.

Instaurar práticas de formação que implementem essas dimensões e indicadores significa construir modelos sociopedagógicos pautados em novas relações sociais e trabalhar processos de mudança psicossociais, estruturais e culturais, a nível intra e interpessoal, grupal e institucional. É na articulação entre esses processos de mudança que vão se constituindo as organizações que aprendem e as pessoas capazes de aprender a aprender, cenário e agentes da sociedade do conhecimento e da informação.

A complexidade dos movimentos do real permite variadas leituras e a expressão de múltiplos vieses, de forma que investigar cientificamente os fenômenos sociais é sempre um processo de aproximação para captar e revelar relações e vislumbrar tendências que ofereçam caminhos a percorrer para fazer avançar a história. Esse foi o objetivo que norteou a revelação das práticas de formação voltadas à competência e à cidadania desencadeadas pelo Serviço Social da Indústria do Rio Grande do Sul.

\section{Referências bibliográficas}

BOURDIEU, Pierre. El oficio de sociólogo. Buenos Aires: Siglo XXI, 1988.

—. O poder simbólico. Rio de Janeiro: Bertrand Brasil, 1989.

- Razões práticas - sobre a teoria da ação. São Paulo: Papirus, 1996.

CANARIO, Rui. (org.). Formação e situações de trabalho. Porto, Portugal: Porto Editora, 1997.

CATTANI, Antônio D. Trabalho e autonomia. Rio de Janeiro: Vozes, 1996.

DESAULNERS, Julieta B. R. "Formação e pesquisa: condições e resultados". Veritas. Porto Alegre: EDIPUCRS, v. 42, n. 2, p. 183-204, jun. 1997.

- . (org.). Formação \& trabalho \& competência. Porto Alegre: EDIPUCRS, 1998.

FLEURY, Maria T. L. "Aprendendo a mudar - aprendendo a aprender". Revista de Administração, São Paulo, v. 30, n. 3, p. 5-11, jul./set. 1995.

FRIGOTTO, Gaudêncio. (org.) Educação e crise do trabalho: perspectivas de final de século. Petrópolis: Vozes, 1998.

MIRANDA, Roberto Lira. Além da inteligência emocional. Rio de Janeiro: Campus, 1997.

MOSCOVICI, Fela. Razão e emoção: a inteligência emocional em questão. Salvador: Casa da Qualidade, 1997. 
SANTOS, Boaventura S. Pelas mäos de Alice: o social e o político na pós-modernidade. 2. ed. São Paulo: Cortez, 1996.

SPINK, Mari J. P. (org.). A cidadania em construção - uma reflexão transdisciplinar. Säo Paulo: Cortez, 1994, p. 105-122.

TANGUY, Lucie. "Formação: uma atividade em vias de definição?" Veritas, Porto Alegre, EDIPUCRS, v. 42, n. 2, p. 385-410, jun. 1996.

\section{ANEXO}

Quadro resumido de operacionalização das categorias centrais

\begin{tabular}{|c|c|c|}
\hline Categoria/Conceito & Dimensões & Indicadores \\
\hline $\begin{array}{l}\text { Formação para a } \\
\text { competência: ações } \\
\text { que visam desenvolver } \\
\text { a capacidade de } \\
\text { articular de modo } \\
\text { eficaz uma } \\
\text { diversidade e } \\
\text { complexidade de } \\
\text { saberes na ação, } \\
\text { expressa em ser capaz } \\
\text { de identificar e } \\
\text { resolver problemas } \\
\text { nas situações de vida } \\
\text { e trabalho. Envolve } \\
\text { uma diversidade de } \\
\text { novas habilidades, } \\
\text { atitudes e } \\
\text { comportamentos } \\
\text { superando o “saber- } \\
\text { fazer" para a } \\
\text { constituição do } \\
\text { "saber-ser" } \\
\text { competente, que é } \\
\text { mensurado a partir de } \\
\text { resultados na ação. }\end{array}$ & $\begin{array}{l}\text { 1. Interdisciplinaridade } \\
\text { 2. Articulação teoria- } \\
\text { prática e cognição- } \\
\text { afeto } \\
\text { 3. Relações } \\
\text { democráticas entre } \\
\text { os agentes sociais } \\
\text { 4. Diversificação do } \\
\text { aporte de saberes } \\
\text { usados no processo } \\
\text { e aprendidos pelos } \\
\text { formandos. } \\
\text { 5. Avaliação por } \\
\text { resultados }\end{array}$ & $\begin{array}{l}\text { 1. saberes disciplinares e de } \\
\text { outras formas de apreensão do } \\
\text { real e atuação interdisciplinar e } \\
\text { interinstitucional } \\
\text { 2. uso de conhecimentos teóricos } \\
\text { com situações práticas, } \\
\text { vivências e experiências, razão } \\
\text { e emoção } \\
\text { 3. trabalho em grupo, participação } \\
\text { no planejamento e } \\
\text { desenvolvimento das } \\
\text { atividades } \\
\text { 4. saberes disciplinares, } \\
\text { institucionais, da experiência, } \\
\text { teórico-práticos, formais e } \\
\text { informais, sociais, } \\
\text { comportamentais e } \\
\text { comunicativos } \\
\text { 5. competência interpessoal, } \\
\text { criatividade; crítica; iniciativa; } \\
\text { liderança; trabalho em equipe; } \\
\text { participação e gestão e } \\
\text { impacto em hábitos, atitudes e } \\
\text { comportamentos do } \\
\text { trabalhador }\end{array}$ \\
\hline
\end{tabular}




\begin{tabular}{|c|c|c|}
\hline $\begin{array}{l}\text { Formação para a } \\
\text { cidadania: ações de } \\
\text { capacitação para } \\
\text { gestão do cotidiano de } \\
\text { forma critica, criativa } \\
\text { e eficaz, a nível } \\
\text { individual e coletivo, } \\
\text { pelo desenvolvimento } \\
\text { intra e interpessoal, } \\
\text { educativo e cultural e } \\
\text { pela participação na } \\
\text { produção e no acesso } \\
\text { aos bens e serviços e } \\
\text { na gestão social, } \\
\text { numa perspectiva de } \\
\text { garantir direitos, } \\
\text { ampliar alternativas e } \\
\text { construir novas } \\
\text { relações sociais. }\end{array}$ & $\begin{array}{l}\text { 1. Diversificação do } \\
\text { aporte de saberes } \\
\text { no processo e de } \\
\text { saberes aprendidos } \\
\text { 2. Articulação entre } \\
\text { teoria e prática e } \\
\text { entre cognição e } \\
\text { afeto } \\
\text { 3. Abordagem e } \\
\text { práticas } \\
\text { interdisciplinares } \\
\text { 4. Participação }\end{array}$ & $\begin{array}{l}\text { 1. saberes sociais, políticos, } \\
\text { comportamentais e } \\
\text { comunicativos, percepção } \\
\text { crítica e global da realidade e } \\
\text { capacidades de comunicação, } \\
\text { negociação, iniciativa e } \\
\text { respeito às diferenças. } \\
\text { 2. abrangência do sentir, pensar e } \\
\text { agir, acesso à informação e } \\
\text { reflexão sobre questões } \\
\text { cotidianas, capacitação para a } \\
\text { ação e desenvolvimento da } \\
\text { autoconfiança e da auto-estima } \\
\text { 3. trabalho interdisciplinar, e/ou } \\
\text { interinstitucional. } \\
\text { 4. participação dos trabalhadores } \\
\text { na gestão institucional e } \\
\text { relações sociais de saber-poder } \\
\text { participativas, respeito, } \\
\text { horizontalidade, construção de } \\
\text { aprendizagem compartilhada }\end{array}$ \\
\hline
\end{tabular}

